\title{
LETTER TO THE EDITOR Lateral Knee Pain Requires a Thorough Assessment and Adequate, Best-Practice Intervention
}

\author{
Alexander T.M. van de Water, B Physio, MSc, PhD \\ Department of Physiotherapy, Academy of Health Care, Saxion University of Applied Sciences, Enschede, The Netherlands
}

\section{Dear Editor:}

The article "Treatment of Lateral Knee Pain Using Soft Tissue Mobilization in Four Female Triathletes" by Winslow in the September 2014 edition of IJTMB, ${ }^{(1)}$ is a good example of a clinical report. As a physiotherapist and clinical researcher, I am interested in the clinical reasoning and interventions used by colleagues.

The clinical study involved four triathletes who had lateral knee pain for more than seven months, and who had undergone prior conservative treatment by other health care professionals. Although the physical assessment and intervention were described and the results for all athletes were positive at completion, I think it is important to discuss the methodology and approach described in this clinical report.

Although the author stresses the importance of "an accurate diagnosis, ruling out other common causes for lateral knee pain" (p.29), the presented information suggests the diagnostic screening was not comprehensive and inconclusive.

Physical assessment comprised merely of single tests of knee ligaments, menisci, and hamstring and iliotibial band flexibility. Apart from the flexibility tests, no test results were presented. In the report (p.25, p.29) it reads that the athletes' "lateral knee pain" was different from iliotibial band syndrome (ITBS). However, the location and severity of the pain experienced during treadmill running was similar to the pain typical for ITBS. Also, the soft tissue mobilization was largely targeted at the ITB.

ITBS has a specific clinical presentation, and is often diagnosed by ruling out other pathologies, history taking, and a specific test, ${ }^{(2)}$ such as Noble's compression test. ${ }^{(3)}$ However, no specific ITBS test was performed, or its results are lacking. Therefore, this report remains unclear with regard to the diagnosis at the time of initiating treatment.

Functional assessment included "squatting and jumping” (p.27), but no results were presented. Treadmill running was performed to assess pain severity only. An extended value would be to evaluate ITBS-related factors such as running technique $(4,5)$ and hip abductor weakness. ${ }^{(6)}$
That a more thorough assessment (of both body structures and active functioning) for accurate diagnosis is preferred, is highlighted by the finding that one patient was left undiagnosed from meniscal problems for more than four weeks (p.29).

The intervention consisted of instruction "to abstain from all physical activity" and "soft tissue mobilization only" (p.28). This intervention seems not an evidence-based or best-practice approach. ${ }^{(2,7-9)}$ To instruct triathletes to abstain from all physical activity for four weeks is not reflective of best-practice. Cardiovascular fitness and other athletic ability will reduce significantly, and other sports including swimming (with no pushing off the wall with the affected leg) might be possible while recovering from lateral knee pain problems.

Soft tissue mobilization I do support when required, but it might be limited as a sole intervention. Soft tissue techniques for ITBS are supported by evidence as part of the intervention, ${ }^{(2,7)}$ but pain control, technique of and biomechanical factors in running and cycling, and involvement of the athlete in their recovery process by using adequate selfmanagement strategies (for example, stretching, foam roller, muscle strengthening) should also be considered. (2,7) $^{(2)}$

In responding to this clinical report, I hope to open discussion on the importance and usefulness of a comprehensive assessment to deduce the cause of the athlete's problem and good clinical, reasoned interventions to treat athletes with lateral knee pain for a speedy, long-lasting return to their full training program.

\section{COPYRIGHT}

Published under the CreativeCommons AttributionNonCommercial-NoDerivs 3.0 License.

\section{REFERENCES}

1. Winslow J. Treatment of lateral knee pain using soft tissue mobilization in four female triathletes. Int $J$ Ther Massage Bodywork. 2014;7(3):25-31. 
2. van der Worp MP, van der Horst N, de Wijer A, Backx FJ, Nijhuis-van der Sanden MW. Iliotibial band syndrome in runners: a systematic review. Sports Med. 2012;42(11):969-992.

3. Noble CA. The treatment of iliotibial band friction syndrome. Br J Sports Med. 1979;13(2):51-54.

4. Allen DJ. Treatment of distal iliotibial band syndrome in a long distance runner with gait re-training emphasizing step rate manipulation. Int J Sports Phys Ther. 2014;9(2):222-231.

5. Meardon SA, Campbell S, Derrick TR. Step width alters iliotibial band strain during running. Sports Biomech. 2012;11(4):464-472.

6. Fredericson M, Cookingham CL, Chaudhari AM, Dowdell BC, Oestreicher N, Sahrmann SA. Hip abductor weakness in distance runners with iliotibial band syndrome. Clin J Sport Med. 2000;10(3):169-175.

7. Fredericson M, Weir A. Practical management of iliotibial band friction syndrome in runners. Clin J Sport Med. 2006;16(3):261-268.
8. Baker RL, Souza RB, Fredericson M. Iliotibial band syndrome: soft tissue and biomechanical factors in evaluation and treatment. $P M \& R$. 2011;3(6):550-561.

9. Strauss EJ, Kim S, Calcei JG, Park D. Iliotibial band syndrome: evaluation and management. J Am Aca Orthop Surg. 2011;19(12):728-736.

Corresponding author: Alexander T. M. van de Water, B Physio, MSc, PhD, Department of Physiotherapy, Academy of Health Care, Saxion University of Applied Sciences, M.H. Tromplaan 28, Postbus 70.000, 7500 KB, Enschede, The Netherlands

E-mail: a.t.m.vandewater@saxion.nl 